\title{
AS CHUVAS DO BAIXO RIO IGUAÇU (SUDOESTE DO PARANÁ) NO PERÍODO DE 1976 A 2016
}

Anderson Borges ${ }^{1}$ Andrey Luis Binda ${ }^{2}$ Rafaela Harumi Fujita ${ }^{3}$

Resumo: A Bacia Hidrográfica do Baixo Rio Iguaçu está localizada no Sudoeste do estado do Paraná e no decorrer dos anos, passou a apresentar importância significativa, sobretudo no que se refere à agropecuária, abastecimento urbano e geração de energia. Contudo, ainda são raras as pesquisas científicas que abordam a área analisada. Frente a isso, o presente trabalho, objetiva caracterizar o regime pluviométrico do Baixo Rio Iguaçu no período de 1976 até 2016. Para tanto, no regime de precipitações, utilizou-se de parâmetros estatísticos de tendência central e o método de interpolação krigagem, a fim de espacializar os dados de chuva de 31 estações pluviométricas. Os resultados destacam a influência do El Niño e da Oscilação Decadal do Pacífico no regime de chuvas da área estudada.

Palavras-chave: Precipitação. El Niño Oscilação Sul. Oscilação Decadal do Pacífico.

\section{THE RAINS ON THE LOWER IGUAÇU RIVER (SOUTHWEST OF PARANÁ) IN THE PERIOD OF 1976 TO 2016}

Abstract: The Lower Iguaçu River Watershed is located in the Southwest of the State of Paraná and over the years, it has become significantly important, especially with regard to agriculture, urban supply and energy generation. However, scientific research that approach this area is still scarce. In this perspective, the present work aims to characterize the rainfall regime of the Lower Iguaçu River in the period of 1976 to 2016. Thus, in the rainfall regime, central tendency statistical parameters and the kriging interpolation method were used, in order to map the rain data from 31 rainfall stations. The results show the influence of El Niño South Oscillation and the Pacific Decadal Oscillation of rainfall in the study area.

Keywords: Rainfall. El Niño South Oscillation. Pacific Decadal Oscillation.

\section{LAS LLUVIAS DEL BAJO RÍO IGUAÇU (SUROESTE DE PARANÁ) EN EL PERÍODO DE 1976 A 2016}

Resumen: La cuenca del Bajo Río Iguaçu se encuentra en el suroeste del estado de Paraná y con los años ha adquirido una importancia significativa, especialmente en lo que respecta a la agricultura, el abastecimiento urbano y la generación de energía. Sin embargo, la investigación científica que aborda el área analizada aún es rara. En vista de esto, el presente estudio tiene como objetivo caracterizar el

\footnotetext{
${ }^{1}$ Universidade Estadual do Oeste do Paraná - UNIOESTE, Departamento de Geografia, Chapecó, Brasil, anderb_8@hotmail.com, https://orcid.org/0000-0001-9639-235X

2 Universidade Federal da Fronteira Sul - UFFS, Curso de Geografia, Chapecó, Brasil, abinda@uffs.edu.br, https://orcid.org/0000-0003-0381-6219

3 Universidade Estadual do Oeste do Paraná - UNIOESTE, Curso de Geografia, Francisco Beltrão, Brasil, rafaela.fujita@unioeste.br, https://orcid.org/0000-0003-1803-7787
} 
régimen de lluvias del Bajo Río Iguaçu entre los años de 1976 a 2016. Por lo tanto, en el régimen de lluvias se utilizaron parámetros estadísticos de tendencia central y el método de interpolación de kriging para presentar los datos de lluvia de 31 estaciones pluviométricas. Los resultados resaltan la influencia de EI Niño Oscilación Sur y la Oscilación Decadal del Pacífico en el régimen de lluvias en el área estudiada.

Palabras clave: Precipitación. El Niño Oscilación Sur. Oscilación Decadal del Pacífico.

\section{Introdução}

O clima é um resultado complexo, que envolve interações que se processam entre a atmosfera e o oceano, com variabilidade tanto no tempo, como no espaço (CONTI, 2000). Desta forma, a atmosfera não é estática e alguns mecanismos de teleconexão exercem influência nos elementos climáticos e variáveis meteorológicas, sobretudo, no que diz respeito ao regime pluviométrico.

A distribuição da precipitação no decorrer do ano é um fator relevante para a sociedade (abastecimento urbano, irrigação de culturas, geração de energia, pesca, lazer, por exemplo). Contudo, dependendo da intensidade das precipitações, elas podem causar efeitos negativos, como inundações e a erosão do solo.

É por isso que o regime pluvial pode ser definido a partir de algumas características principais, como: o total, a duração, a distribuição temporal e espacial. A precipitação ocorre de maneira aleatória, não permitindo uma previsão determinística com antecedência ${ }^{4}$ (BERTONI; TUCCI, 2009).

A variabilidade pluvial na Região Sul do Brasil é influenciada por diversos fenômenos, alguns deles decorrem, justamente, das interações oceano-atmosfera. Esses fenomênos podem ser observados a partir da alteração na Temperatura da Superfície do Mar (TSM), ocorrendo de maneira interanual, a exemplo do El Niño Oscilação Sul (ENOS) (OLIVEIRA, 1999; MENDONÇA e DANNI-OLIVEIRA, 2007), ou decadal, como a Oscilação Decadal do Pacífico (ODP) (MOLION, 2005; KAYANO; ANDREOLI, 2009). Assim, estudos relacionando a precipitação e os mecanismos de teleconexões são importantes em todas as escalas (global, regional e local), pois tanto o ENOS como a ODP exercem influência diferenciada, dependendo do período e da localização geográfica (SILVA; CAMPOS, 2011).

\footnotetext{
${ }^{4}$ Com todo o aparato tecnológico existente na atualidade, é possível prever com antecedência as chuvas "frontais".
} 
O ENOS, a partir das variações de TSM do oceano Pacífico Tropical, imprime alterações nos campos de pressão na direção Leste-Oeste, chamadas de Oscilação Sul (OS), que influência, por sua vez, diretamente a circulação geral da atmosfera (CGA), causando alterações climáticas cíclicas em diversos locais do planeta. $O$ fenômeno apresenta duas fases: uma quente, denominada El Niño propriamente dito, e outra fria, denominada La Niña, que ocorrem com uma frequência variável de 3 a 7 anos e com duração de 6 a 18 meses. As anomalias de TSM podem variar de $1^{\circ} \mathrm{C}$ a $6^{\circ} \mathrm{C}$ acima/abaixo da média térmica, que é $23^{\circ} \mathrm{C}$ (MENDONÇA; DANNIOLIVEIRA, 2007, OLIVEIRA, 1999, ANDRADE, 2003).

Na Região Sul, Andrade (2003, p.11), com base em Grimm et al. (1997), afirma que durante o El Niño os jatos subtropicais (ventos em altos níveis) são intensificados, em decorrência do aumento do gradiente de temperatura entre o Equador e os Polos. Esse fortalecimento dos jatos subtropicais cria condições para bloqueio atmosférico que afeta o deslocamento dos sistemas frontais, tornando-os estacionários na Região Sul. Com isso, há um aumento das chuvas nesta região, principalmente na primavera do ano que o fenômeno se inicia e no outono/inverno do ano seguinte.

Assim como o ENOS, a ODP também apresenta duas fases. A fase fria é caracterizada por anomalias negativas na TSM do Pacífico Tropical e anomalias positivas na TSM do Pacífico Extratropical. Já a fase quente é marcada por configurações contrárias, anomalias de TSM positivas no Pacífico Tropical e negativas no Pacífico Extratropical. As causas e as consequências da ODP ainda são uma incógnita. Contudo, a atmosfera sofre aquecimento por debaixo, desta maneira, "os oceanos são a condição de contorno inferior mais importante para o clima e, certamente, o Pacífico, por ocupar um terço da superfície terrestre, deve ter um papel preponderante na variabilidade climática interdecadal" (MOLION, 2005, p.1).

Kayano e Andreoli (2009, p.375) definem a ODP como "Oscilação Decenal do Pacífico". Para os autores, o fenômeno ocorre com espaço de tempo de 20 a 30 anos e com mudanças abruptas de uma fase para outra. Um aspecto salutar é que durante a fase fria da ODP, a sucessão de episódios associados ao ENOS tende a ter frequências equivalentes, porém na fase quente da ODP os eventos de El Niño são mais frequentes e intensos. 
A influência desses fenômenos de escala global nos totais anuais de chuva da bacia hidrográfica do Baixo Rio Iguaçu (BHBRI) podem representar prejuízos para a sociedade e, desta forma, entender a dinâmica das chuvas auxilia nas mais diversas áreas, como econômica e social. Assim, percebe-se que há necessidade de se ampliar os estudos sobre o regime pluviométrico da bacia hidrográfica do Baixo Rio Iguaçu, analisando possíveis anomalias ao longo do tempo. Desta maneira, este trabalho propõe, como objetivo central, caracterizar o regime de chuvas na BHBRI no período de 1976 a 2016.

\section{Materiais e Métodos}

A Bacia Hidrográfica do Iguaçu é a maior do estado do Paraná, com cerca de $57.329 \mathrm{~km}^{2}$ (desconsiderando os afluentes da margem Catarinense) e aproximadamente $910 \mathrm{~km}$ de extensão, da nascente até sua foz (MAACK, 1981). É dividida em três seções: alto, médio e baixo Iguaçu. Neste trabalho, o enfoque será dado ao baixo curso do rio Iguaçu, que drena uma área de $26.552 \mathrm{~km}^{2}$ em seu trajeto de pouco mais de $483 \mathrm{~km}$ de extensão. Geograficamente, está situada na Região Sudoeste do estado do Paraná, com picos de altitude nas nascentes do rio Chopim $(1.300 \mathrm{~m})$, sudeste da bacia, no município de Palmas/PR e nordeste da bacia, nas nascentes do Rio Cavernoso (980m), próximo a Guarapuava/PR).

Os dados anuais de precipitação da BHBRI foram obtidos por meio do acesso ao banco de dados do Instituto das Águas do Paraná (AGUASPARANÁ) e da Agência Nacional de Águas (ANA). A série histórica de precipitação diária corresponde ao período de 1976 a 2016, compreendendo 41 anos de dados de 31 estações pluviométricas (Quadro 1 e Figura 1). Os dados cartográficos foram adquiridos por download no site do Instituto Brasileiro de Geografia e Estatística (IBGE) e Instituto de Terras, Cartografia e Geologia do Paraná (ITCG).

Quadro 1 - Dados das estações pluviométricas.

\begin{tabular}{|c|c|c|c|c|c|}
\hline $\mathbf{N}$ & Código & Nome (altitude) & Operador & Latitude & Longitude \\
\hline 1 & 2553015 & Planalto (400m) & IAPAR & $-25 \div 42^{\prime} 0^{\prime \prime}$ & $-53^{\circ} 46^{\prime} 0^{\prime \prime}$ \\
\hline 2 & 2553030 & Três Barras do Paraná (534m) & AGUASPARANÁ & $-25^{\circ} 25^{\prime} 0 "$ & $-53^{\circ} 11^{\prime} 0^{\prime \prime}$ \\
\hline 3 & 2652007 & Porto Palmeirinha-396 (560m) & COPEL & $-26 \div 01^{\prime} 46 "$ & $-52^{\circ} 37^{\prime} 42^{\prime \prime}$ \\
\hline 4 & 2652015 & Salto Claudelino $(800 \mathrm{~m})$ & ANA & $-26 \div 16^{\prime} 41^{\prime \prime}$ & $-52^{\circ} 17^{\prime} 46^{\prime \prime}$ \\
\hline 5 & 2653024 & Ponte Marmeleiro (640m) & AGUASPARANÁ & $-26 \div 09^{\prime} 09^{\prime \prime}$ & $-53^{\circ} 01^{\prime} 06^{\prime \prime}$ \\
\hline 6 & 2652010 & Palmas (1060m) & AGUASPARANÁ & $-26^{\circ} 29^{\prime} 0^{\prime \prime}$ & $-52^{\circ} 0^{\prime} 0^{\prime \prime}$ \\
\hline
\end{tabular}




\begin{tabular}{|c|c|c|c|c|c|}
\hline 7 & 2552031 & Bugre (650m) & AGUASPARANÁ & |-254' & $\mid-52^{\circ} 24^{\prime} 57^{\prime \prime}$ \\
\hline 8 & 2552036 & Rio Bonito do Iguaçu (704m) & AGUASPARANÁ & $-25^{\circ} 29^{\prime} 23^{\prime \prime}$ & $-52^{\circ} 31^{\prime} 56^{\prime \prime}$ \\
\hline 9 & 2653008 & Barracão $(835 \mathrm{~m})$ & AGUASPARANÁ & $-26^{\circ} 15^{\prime} 00^{\prime \prime}$ & $-53^{\circ} 37^{\prime} 59^{\prime \prime}$ \\
\hline 10 & 2553044 & Enéas Marques (585m) & AGUASPARANÁ & $-25^{\circ} 55^{\prime} 59^{\prime \prime}$ & $-53^{\circ} 10^{\prime} 11^{\prime \prime}$ \\
\hline 11 & 2552029 & São joão do Oeste (680m) & AGUASPARANÁ & $-25^{\circ} 49^{\prime} 30^{\prime \prime}$ & $-52^{\circ} 43^{\prime} 49^{\prime \prime}$ \\
\hline 12 & 2552024 & Candói $(750 \mathrm{~m})$ & AGUASPARANÁ & $-25^{\circ} 37^{\prime} 00^{\prime \prime}$ & $-52^{\circ} 04^{\prime} 00^{\prime \prime}$ \\
\hline 13 & 2553036 & Nova Esperança (400m) & AGUASPARANÁ & $-25^{\circ} 57^{\prime} 00^{\prime \prime}$ & $-53^{\circ} 49^{\prime} 59^{\prime \prime}$ \\
\hline 14 & 2553012 & Ampére $(330 \mathrm{~m})$ & AGUASPARANÁ & $-25^{\circ} 54^{\prime} 48^{\prime \prime}$ & $-53^{\circ} 28^{\prime} 23^{\prime \prime}$ \\
\hline 15 & 2653019 & Rio Verde $(700 \mathrm{~m})$ & AGUASPARANÁ & $-26^{\circ} 14^{\prime} 30^{\prime \prime}$ & $-53^{\circ} 11^{\prime} 47^{\prime \prime}$ \\
\hline 16 & 2652025 & São Carvajo $(815 \mathrm{~m})$ & AGUASPARANÁ & $-26^{\circ} 17^{\prime} 21^{\prime \prime}$ & $-52^{\circ} 41^{\prime} 52^{\prime \prime}$ \\
\hline 17 & 2553004 & Cruzeiro do Iguaçu (450m) & AGUASPARANÁ & $-25^{\circ} 34^{\prime} 50^{\prime \prime}$ & $-53^{\circ} 07^{\prime} 03^{\prime \prime}$ \\
\hline 18 & 2552041 & Cantagalo $(800 \mathrm{~m})$ & ANA & $-25^{\circ} 22^{\prime} 00^{\prime \prime}$ & $-52^{\circ} 07^{\prime} 00^{\prime \prime}$ \\
\hline 19 & 2552026 & Goioxim (858m) & AGUASPARANÁ & $-25^{\circ} 11^{\prime} 59^{\prime \prime}$ & $-51^{\circ}-59^{\prime} 27^{\prime \prime}$ \\
\hline 20 & 2552006 & Guaraniaçu (920m) & AGUASPARANÁ & $-25^{\circ} 04^{\prime} 59^{\prime \prime}$ & $-52^{\circ} 52^{\prime} 59^{\prime \prime}$ \\
\hline 21 & 2553016 & Nelson Taborda $(828 \mathrm{~m})$ & AGUASPARANÁ & \begin{tabular}{|l|l|l}
$-25^{\circ} 11^{\prime} 01^{\prime \prime}$ \\
\end{tabular} & $-53^{\circ} 28^{\prime} 49^{\prime \prime}$ \\
\hline 22 & 2453023 & Cascavel - OCEPAR $(760 \mathrm{~m})$ & IAPAR & $-24^{\circ} 55^{\prime} 59^{\prime \prime}$ & $-53^{\circ} 25^{\prime} 59^{\prime \prime}$ \\
\hline 23 & 2553009 & Céu Azul (610m) & AGUASPARANÁ & $-25^{\circ} 09^{\prime} 21^{\prime \prime}$ & $-53^{\circ} 51^{\prime} 00^{\prime \prime}$ \\
\hline 24 & 2554018 & Jardinópolis (291m) & AGUASPARANÁ & $-25^{\circ} 24^{\prime} 48^{\prime \prime}$ & $-54^{\circ} 02^{\prime} 14^{\prime \prime}$ \\
\hline 25 & 2554006 & São Miguel do Iguaçu (309m) & AGUASPARANÁ & $-25^{\circ} 20^{\prime} 45^{\prime \prime}$ & $-54^{\circ} 14^{\prime} 37^{\prime \prime}$ \\
\hline 26 & 2554002 & Salto Cataratas (152m) & AGUASPARANÁ & $-25^{\circ} 40^{\prime} 59^{\prime \prime}$ & $-54^{\circ} 25^{\prime} 59^{\prime \prime}$ \\
\hline 27 & 2553024 & Capitão L. Marques (264m) & ANA & $-25^{\circ} 28^{\prime} 59^{\prime \prime}$ & $-53^{\circ} 37^{\prime} 00^{\prime \prime}$ \\
\hline 28 & 2653001 & Campo Erê $(920 \mathrm{~m})$ & ANA & $-26^{\circ} 26^{\prime} 48^{\prime \prime}$ & $-53^{\circ} 04^{\prime} 49^{\prime \prime}$ \\
\hline 29 & 2554027 & Foz do Iguaçu - Novo (105m) & ANA & $-25^{\circ} 30^{\prime} 00^{\prime \prime}$ & $-54^{\circ} 36^{\prime} 00^{\prime \prime}$ \\
\hline 30 & 2551040 & Turvo $(1146 \mathrm{~m})$ & ANA & $-25^{\circ} 02^{\prime} 26 "$ & $-51^{\circ} 32^{\prime} 39^{\prime \prime}$ \\
\hline 31 & 2651036 & Quilometro $30(1133 \mathrm{~m})$ & ANA & $-26^{\circ} 46^{\prime} 33^{\prime \prime}$ & $-51^{\circ}-15^{\prime} 46^{\prime \prime}$ \\
\hline
\end{tabular}

Fonte: ANA (2019). 
Figura 1 - Localização das estações pluviométricas.

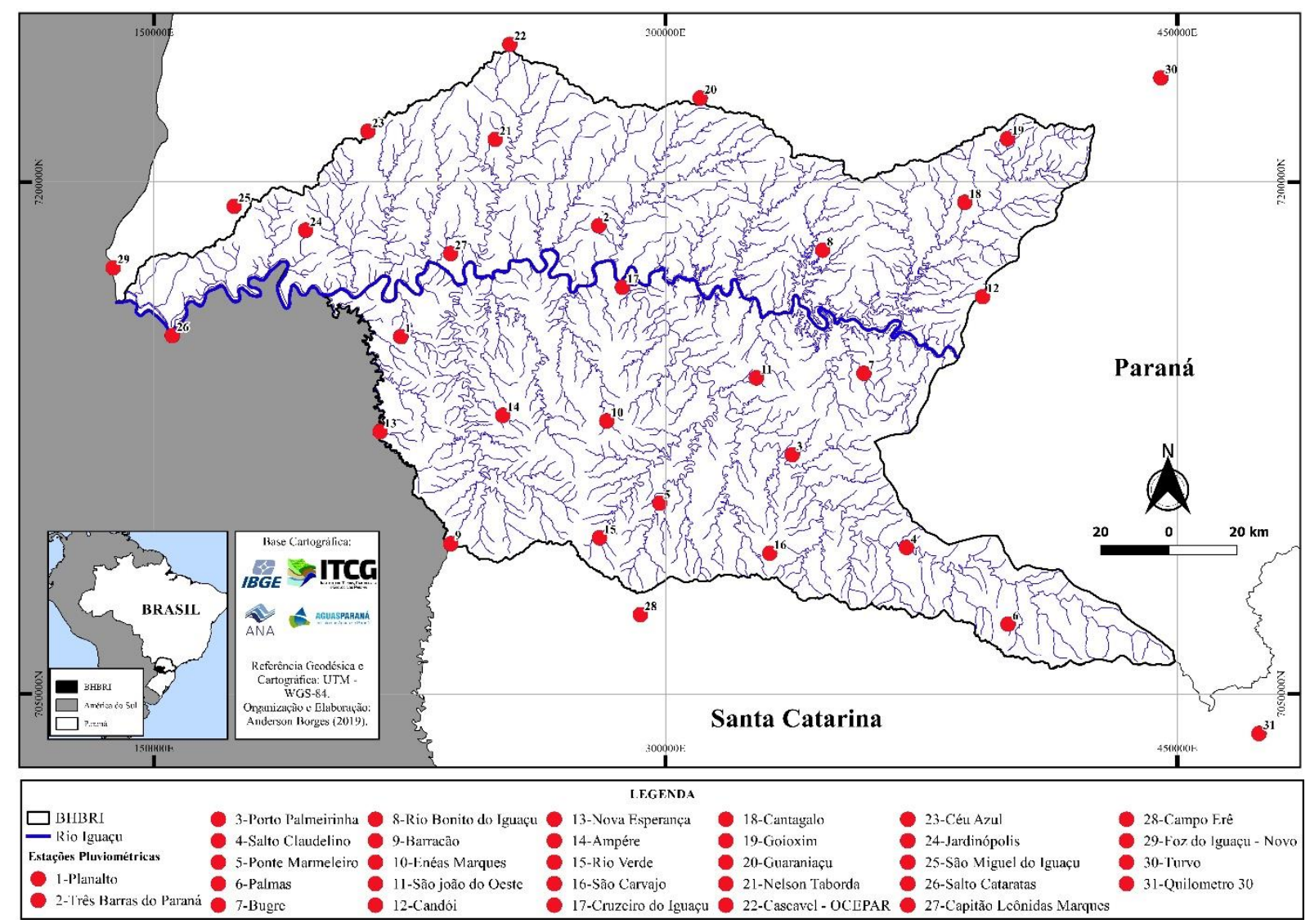

Fonte: ANA (2019).

Os critérios de escolha das estações foram: localização na BHBRI ou adjacências e a qualidade dos dados, sobretudo no que se refere aos períodos de falhas. Antunes (2015), baseado na "Organização Meteorológica Mundial", estabeleceu em seu estudo um raio de distanciamento de 13,5 km entre as estações pluviométricas por ele estudadas, porém, na BHBRI o número de estações é reduzido, desta forma foi adotado um raio de $30 \mathrm{Km}$. As seções fora da área de estudo auxiliam nos mapas de isoietas, visando preencher toda área da bacia.

O período abordado (1976-2016) foi definido conforme os dados disponíveis e compreendendo um período mínimo de 30 anos. Entretanto, estações pluviométricas com informações anterior a 1976 e/ou após 2016 são raras.

A organização dos dados e os parâmetros estatísticos utilizados no trabalho são baseados em Zavattini e Boin (2013). A média aritmética foi calculada pela equação 1:

$$
X=\sum_{1 \text { an }} / n \quad \cdots(\text { Equação } 1)
$$


Onde $\mathbf{X}=$ média aritmética; $\Sigma=$ somatória dos dados, do primeiro ao enésimo; $\mathbf{n}=$ número de ocorrências.

O Desvio-padrão (S) foi calculado conforme equação 2:

$$
S=\frac{\sqrt{\sum_{11 a n}(x i-X)^{2}}}{n} \quad \ldots(\text { Equação 2) }
$$

Onde $x i=0$ valor individual de cada dado; $X=$ média aritmética; $\Sigma=$ somatória dos dados do primeiro ao enésimo; $n=$ número de ocorrências.

O Coeficiente de variação (CV) é uma medida de dispersão relativa, em que o resultado é dado em porcentagem (\%). É calculado conforme a equação 3 :

$$
C V=(S / X)^{*} 100 \ldots(\text { Equação } 3)
$$

Onde $\mathrm{S}=$ desvio padrão; $\mathrm{X}=$ média aritmética.

Os mapas anuais de precipitação foram confeccionados no software Surfer $\AA^{5}$ versão 8.0, e a finalização dos mapas no $Q G I S B^{6}$ versão 2.18 .17 (2019). O método de interpolação utilizado foi a Krigagem, uma vez que "este não é um simples método de interpolação estocástico pois utiliza geoestatística para efetuar a interpolação, o que em muitos casos é uma grande vantagem sobre outros métodos" (MAZZINI; SCHETTINI, 2009, p.57). Essa forma de interpolação foi escolhida por ter apresentado resultados satisfatórios em outros estudos e facilidade no manuseio dos dados (CARVALHO; ASSAD, 2005, VIOLA et al., 2010, ALVES; VECCHIA, 2011).

Para verificar qual fenômeno (El Niño e La Niña) prevaleceu em determinado ano, "considerou-se o período máximo de cada uma das condições e tratou-se como um ano representativo aquele que tivesse no mínimo seis meses sob sua atuação (BINDA, 2016, p.99). Desta forma, em um ano de El Niño Forte, a TSM ficou no mínimo seis meses $1,5^{\circ} \mathrm{C}$ acima da média.

Por fim, com a intenção de verificar se o regime de chuvas sofre influência dos fenômenos de escala global, ENOS e ODP, serão comparados os resultados da 
distribuição das isoietas anuais com a Temperatura da Superfície do Mar (TSM) em "Niño 3.4".

Os dados de anomalia de temperatura do oceano Pacífico foram obtidos na National Oceanic and Atmospheric Administration (NOAA) e apresentam a média ponderada $^{7}$ de cada mês.

\section{Resultados}

Os mapas a seguir representam a média anual (Figura 2-A), o desvio padrão (Figura 2-B) e o coeficiente de variação (Figura 2-C) da precipitação da BHBRI entre os anos de 1976 e 2016.

Em relação à precipitação, a média anual da BHBRI (Figura 2-A) oscila entre 1.750 e $2.100 \mathrm{~mm}$. Os menores valores (abaixo de $1.800 \mathrm{~mm}$ ) se limitam ao extremo oeste da bacia, próximo à divisa com o Paraguai. Na área central a precipitação varia entre 1.800 e $2.000 \mathrm{~mm}$ anuais. As maiores médias anuais (entre $2.000 \mathrm{e}$ $2.100 \mathrm{~mm}$ ) de precipitação se localizam na região sul, sudeste, sudoeste e pontos ao norte e nordeste da bacia.

O desvio padrão (S) da precipitação da BHBRI (Figura 2-B) apresenta variações de 350 a $500 \mathrm{~mm}$ anuais. Os menores valores (350 mm) estão localizados ao norte do rio Iguaçu, enquanto os maiores, concentram-se, principalmente, no sul e sudoeste, com destaque para um ponto a nordeste, onde pode chegar a $500 \mathrm{~mm}$. Na porção noroeste oscila entre 350 e 400 mm, já na porção central e sudeste da bacia alterna entre 400 e $450 \mathrm{~mm}$.

Acerca do coeficiente de variação (Figura 2-C) do regime de chuvas, na BHBRI é de 20 a 22\% na área central, oeste e sudeste. Os espaços que apresentam coeficiente acima de $22 \%$ estão no sul e sudeste da bacia, além de alguns pontos isolados na área central e a nordeste, com destaque ao ponto a nordeste que apresenta coeficiente superior a $24 \%$. Os menores valores $(<18 \%)$ ficam ao norte do rio Iguaçu, em pontos isolados.

\footnotetext{
${ }^{7}$ Média ponderada utiliza dados de três meses, o mês base, um antes e um depois. Exemplo, para calcular a média de janeiro de 1976: é somado a média mensal de dezembro/1975, janeiro/1976 e fevereiro/1976 e divide-se por três.
} 
Figura 2 - Mapa dos parâmetros estatísticos (média, S e CV)
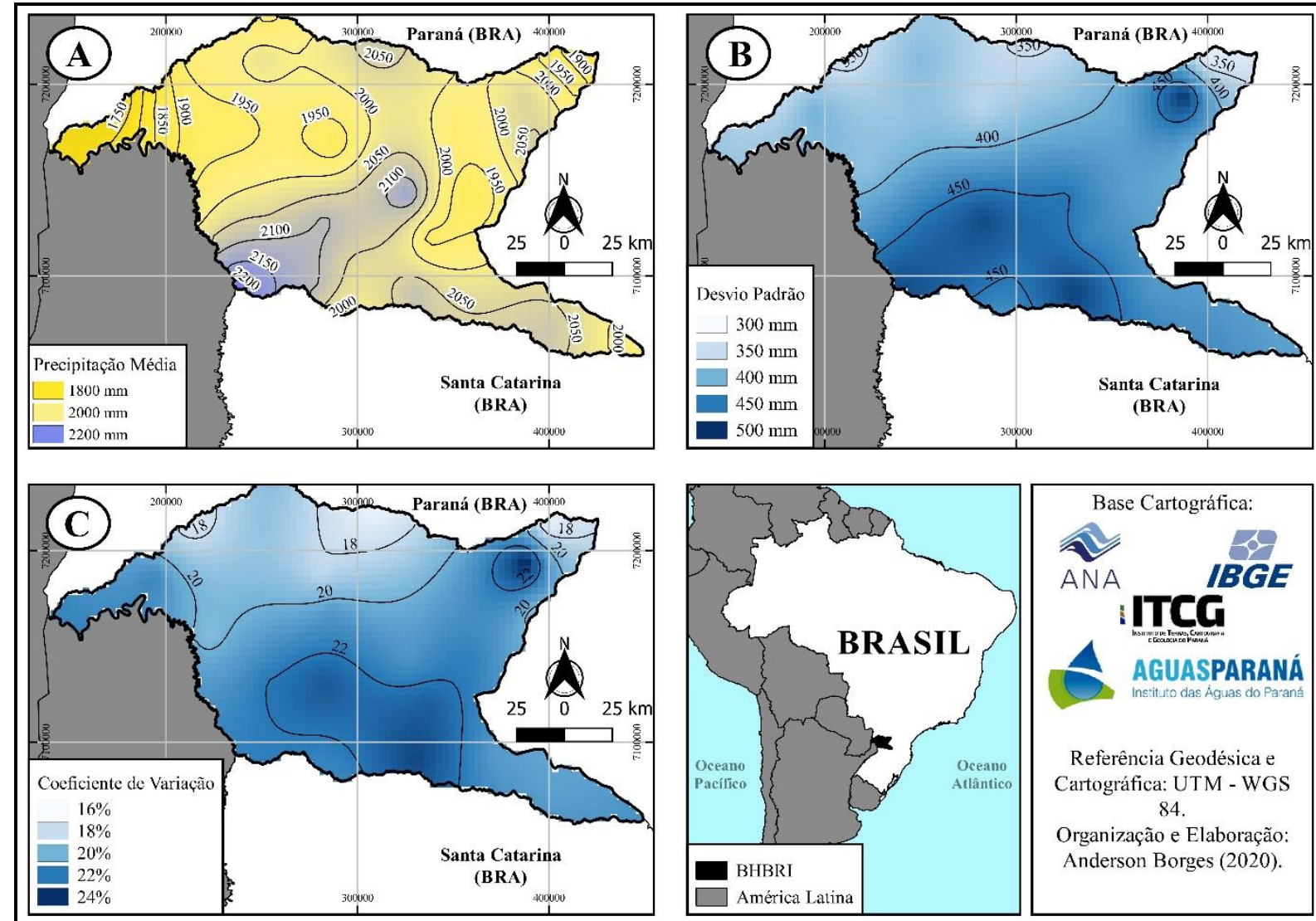

Base Cartográfica:

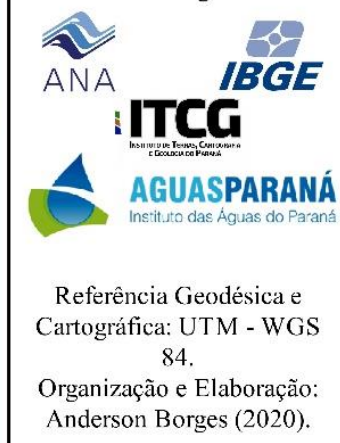

ANA (2019).

Os totais anuais de precipitação da BHBRI estão expostos nas Figuras 3 e 4, com curvas de isoietas de $200 \mathrm{~mm}$. As cores variam de amarelo escuro $(<1.200 \mathrm{~mm}$ ) até azul escuro ( $>3.200 \mathrm{~mm}$ ) e permitem uma análise da variabilidade espacial das chuvas na área de estudo. 
Figura 3 - Mapa anual de isoietas da BHBRI (1976-1998)

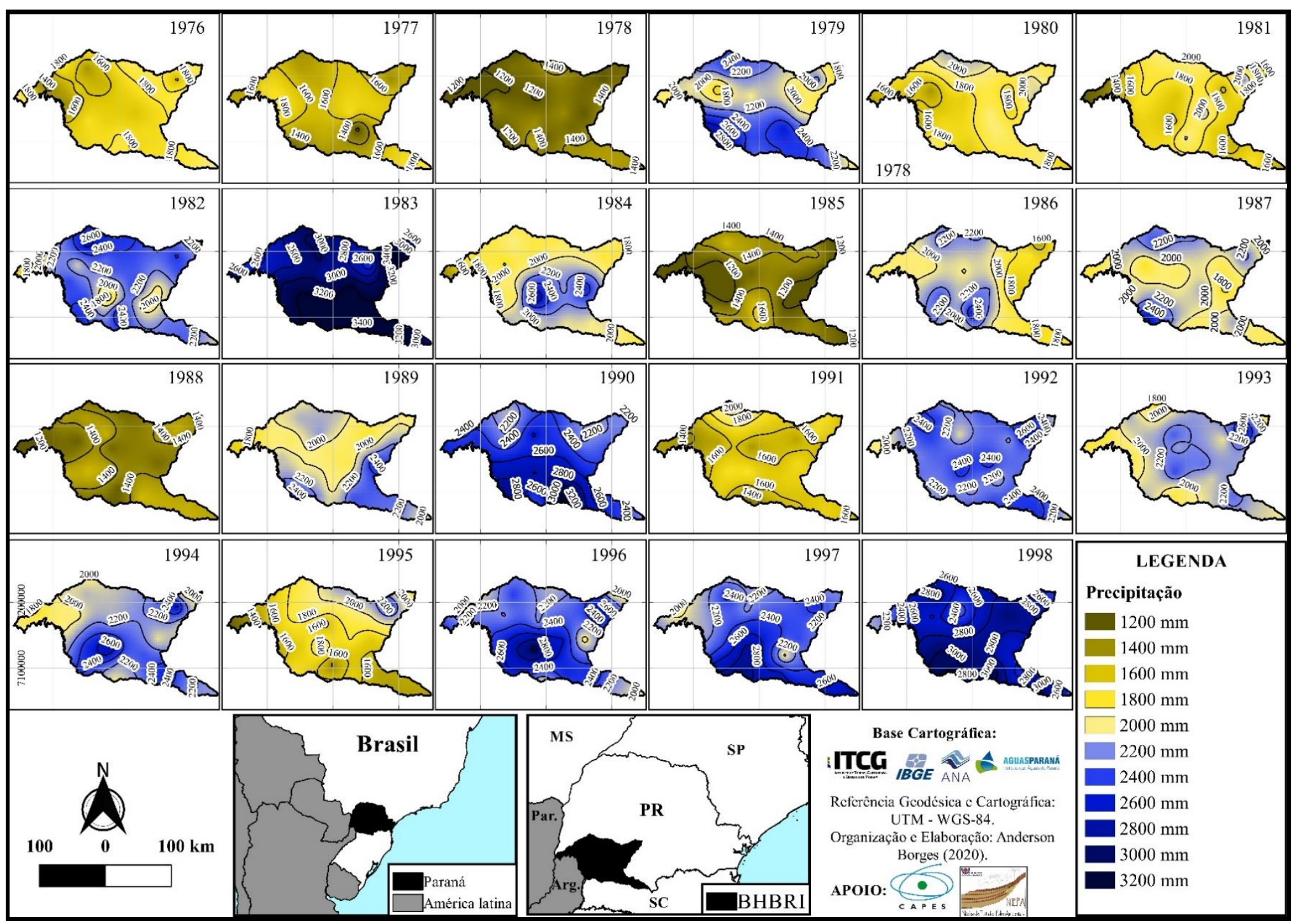

Fonte: ANA (2020). 
Figura 4 - Mapa anual de isoietas da BHBRI (1999-2016)

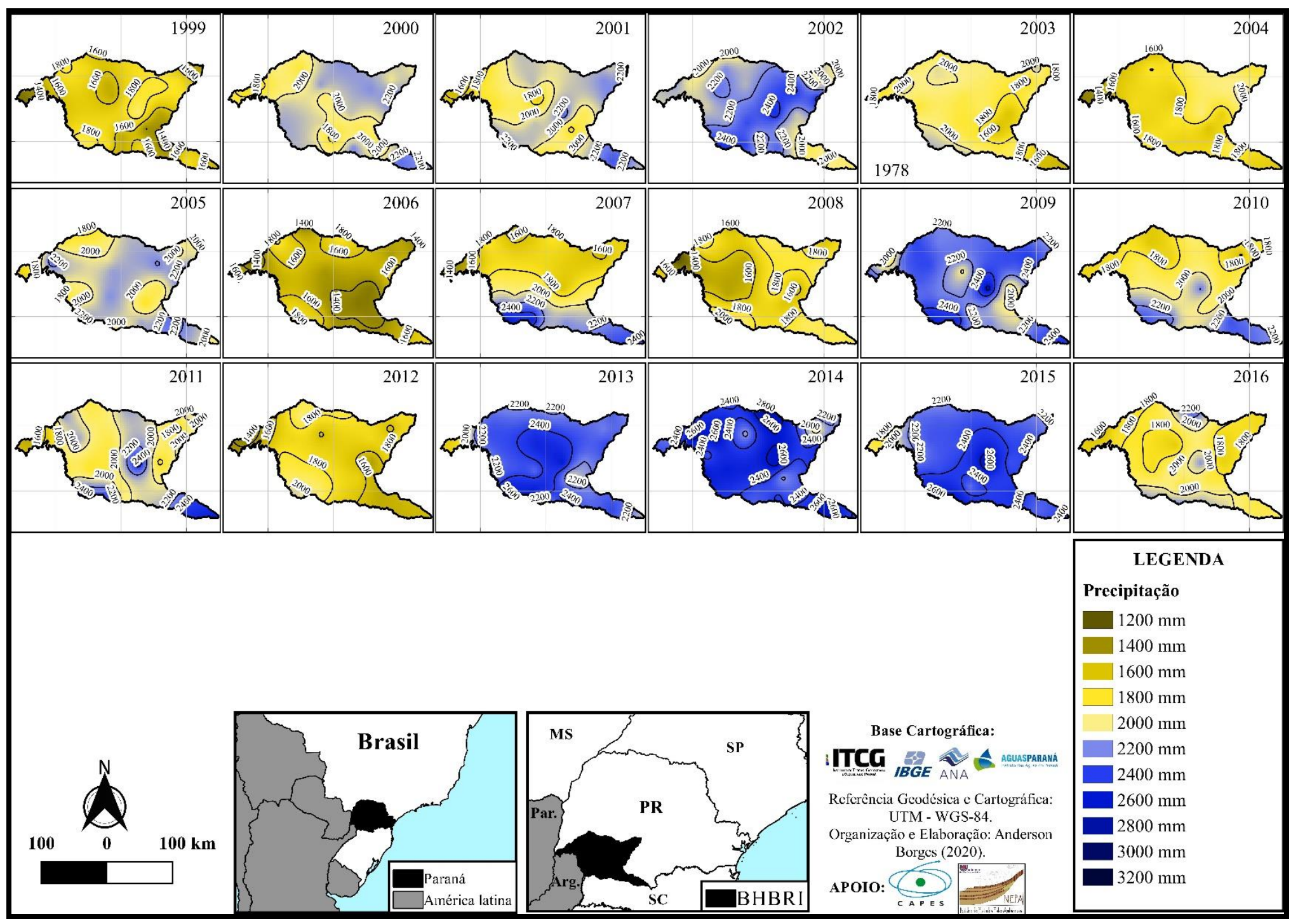

Fonte: ANA (2020). 
Optou-se por discriminar a pluviosidade anual em anos chuvosos $(>2.400$ $\mathrm{mm})$ e secos $(<1.600 \mathrm{~mm})$, considerando a precipitação média ${ }^{8}$ anual $(2.000 \mathrm{~mm})$ e o desvio padrão $(400 \mathrm{~mm}$ ). Ainda, com objetivo de verificar a possível influência do ENOS, os dados anuais de precipitação são comparados à variação da TSM do período.

As descrições dos resultados são apresentadas no Quadro 2. Nele destacase o ano, a variação da TSM naquele período (NOAA, 2019), a influência do fenômeno ENOS (El Niños em Vermelho e La Niñas em azul), a fase da ODP (Fase Quente em vermelho e Fase Fria em azul) (MOLION, 2005) e as principias características apresentadas pelo regime de precipitação.

Quadro 2 - Resumo das principais características de cada ano da série.

\begin{tabular}{|c|c|c|c|c|}
\hline Ano & TSM & Evento & ODP & Características \\
\hline 1976 & $\begin{array}{l}-1,2 \mathrm{a} \\
0,8^{\circ} \mathrm{C}\end{array}$ & & $\begin{array}{l}\text { Fase } \\
\text { Quente }\end{array}$ & $\begin{array}{c}\text { Precipitação abaixo da média, variando } \\
\text { de } 1.400 \text { a } 1.800 \mathrm{~mm} \text {. Os maiores } \\
\text { valores }(>1.800 \mathrm{~mm} \text { ) se localizam nas } \\
\text { áreas mais elevadas da bacia, próximo à } \\
\text { divisa com o estado de Santa Catarina e } \\
\text { nas nascentes do rio Cavernoso (próximo } \\
\text { à Guarapuava-PR). Os menores valores } \\
(<1.600 \mathrm{~mm} \text { ) estão próximos à foz do rio } \\
\text { Iguaçu. }\end{array}$ \\
\hline 1977 & $\begin{array}{l}0,3 \mathrm{a} \\
0,8^{\circ} \mathrm{C}\end{array}$ & $\begin{array}{c}\text { El Niño } \\
\text { Fraco }\end{array}$ & $\begin{array}{l}\text { Fase } \\
\text { Quente }\end{array}$ & $\begin{array}{l}\text { Os totais anuais permaneceram abaixo } \\
\text { da média, com valores entre } 1.400 \text { e } \\
1.800 \mathrm{~mm} \text {. As regiões com os maiores } \\
\text { totais }(>1.800 \mathrm{~mm} \text { ) estão em pontos } \\
\text { isolados a oeste (próximo a Capanema- } \\
\text { PR) e sudeste, próximo à Palmas-PR. Os } \\
\text { menores valores }(<1.400 \mathrm{~mm} \text { ) estão a } \\
\text { sudoeste, na divisa com Santa Catarina e } \\
\text { na área central da bacia do Chopim. }\end{array}$ \\
\hline 1978 & $\begin{array}{l}-0,5 \mathrm{e} \\
- \\
0,2^{\circ} \mathrm{C}\end{array}$ & & $\begin{array}{l}\text { Fase } \\
\text { Quente }\end{array}$ & $\begin{array}{l}\text { Consiste no ano mais seco da série } \\
\text { histórica. A precipitação total anual ficou } \\
\text { entre } 1.200 \text { e } 1.400 \mathrm{~mm} \text {, com os maiores } \\
\text { valores }(>1.400 \mathrm{~mm} \text { ) localizados em } \\
\text { pontos isolados, a sul, sudeste, sudoeste } \\
\text { e norte. Os menores valores }(<1.200 \\
\text { mm) estão também em pontos isolados a } \\
\text { oeste e na área central da bacia. }\end{array}$ \\
\hline 1979 & $\begin{array}{l}0,1 \mathrm{a} \\
0,7^{\circ} \mathrm{C}\end{array}$ & & $\begin{array}{l}\text { Fase } \\
\text { Quente }\end{array}$ & $\begin{array}{l}\text { As chuvas oscilaram muito, variando de } \\
1.800 \text { a } 2.800 \mathrm{~mm} \text {. Os maiores valores } \\
\text { (entre } 2.200 \text { e } 2.800 \mathrm{~mm} \text { ) se localizam }\end{array}$ \\
\hline
\end{tabular}

\footnotetext{
${ }^{8}$ Precipitação média e desvio padrão aproximados da BHBRI.
} 


\begin{tabular}{|c|c|c|c|c|}
\hline & & & & $\begin{array}{l}\text { nas regiões sul e sudoeste e acima de } \\
2.200 \mathrm{~mm} \text { no norte, próximo à Cascavel- } \\
\text { PR. Os valores abaixo de } 2.200 \mathrm{~mm} \\
\text { encontram-se na calha do rio Iguaçu e } \\
\text { nas áreas mais elevadas, próximo à } \\
\text { Palmas-PR e Guarapuava-PR. }\end{array}$ \\
\hline 1980 & $\begin{array}{l}-0,1 \mathrm{a} \\
0,5^{\circ} \mathrm{C}\end{array}$ & & $\begin{array}{l}\text { Fase } \\
\text { Quente }\end{array}$ & $\begin{array}{c}\text { A precipitação variou de } 1.600 \text { a } 2.000 \\
\text { mm, com pontos isolados apresentando } \\
\text { valores acima de } 2.000 \mathrm{~mm} \text { (norte e } \\
\text { nordeste da bacia) e abaixo de } 1.600 \mathrm{~mm} \\
\text { (a oeste) }\end{array}$ \\
\hline 1981 & $\begin{array}{l}-0,2 \mathrm{a} \\
0,5^{\circ} \mathrm{C}\end{array}$ & & $\begin{array}{l}\text { Fase } \\
\text { Quente }\end{array}$ & $\begin{array}{l}\text { Os totais anuais apresentaram variação } \\
\text { de } 1.400 \text { a } 2.000 \mathrm{~mm} \text {, com os maiores } \\
\text { valores }(2.000 \mathrm{~mm}) \text { localizados na área } \\
\text { central e nordeste da bacia, e os } \\
\text { menores valores situam-se na região da } \\
\text { foz do rio lguaçu. }\end{array}$ \\
\hline 1982 & $\begin{array}{l}0,1 \mathrm{a} \\
2^{\circ} \mathrm{C}\end{array}$ & $\begin{array}{l}\text { El Niño } \\
\text { Moderado }\end{array}$ & $\begin{array}{l}\text { Fase } \\
\text { Quente }\end{array}$ & $\begin{array}{l}\text { Um ano chuvoso, com precipitações } \\
\text { oscilando entre } 1.800 \text { e } 2.600 \mathrm{~mm} \text {. A } \\
\text { área com maior concentração de chuva } \\
\text { (> } 2.600 \mathrm{~mm} \text { ) está ao norte do rio lguaçu. } \\
\text { Já os menores índices }(<1.800 \mathrm{~mm}) \text { se } \\
\text { localizam no extremo oeste e um ponto } \\
\text { isolado na área central. }\end{array}$ \\
\hline 1983 & $\begin{array}{l}-1 \mathrm{a} \\
2^{\circ} \mathrm{C}\end{array}$ & $\begin{array}{l}\text { El Niño } \\
\text { Moderado }\end{array}$ & $\begin{array}{l}\text { Fase } \\
\text { Quente }\end{array}$ & $\begin{array}{l}\text { É o ano mais chuvoso da série, com as } \\
\text { precipitações oscilando entre } 2.600 \text { e } \\
3.400 \mathrm{~mm} \text {. Os maiores valores }(>3.200 \\
\mathrm{mm}) \text { situam-se nas áreas mais elevadas } \\
\text { ao sul e a nordeste da bacia. As áreas } \\
\text { próximas da calha do rio lguaçu exibiram } \\
\text { os menores valores }(<2.600 \mathrm{~mm})\end{array}$ \\
\hline 1984 & $\begin{array}{l}-1 \mathrm{a}- \\
0,3^{\circ} \mathrm{C}\end{array}$ & & $\begin{array}{l}\text { Fase } \\
\text { Quente }\end{array}$ & $\begin{array}{c}\text { As chuvas apresentaram variação de } \\
1.600 \text { a } 2.600 \mathrm{~mm} \text {, com os valores mais } \\
\text { elevados }(>2.400 \mathrm{~mm}) \text { localizados na } \\
\text { área central e a leste da bacia. Os } \\
\text { valores inferiores a } 1.800 \mathrm{~mm} \text { estão } \\
\text { situados em pontos isolados a nordeste e } \\
\text { oeste. }\end{array}$ \\
\hline 1985 & $\begin{array}{c}-1,1 \mathrm{a} \\
- \\
0,3^{\circ} \mathrm{C}\end{array}$ & $\begin{array}{l}\text { La Niña } \\
\text { Fraco }\end{array}$ & $\begin{array}{l}\text { Fase } \\
\text { Quente }\end{array}$ & $\begin{array}{c}\text { Um ano seco, com precipitações } \\
\text { variando entre } 1.200 \text { e } 1.600 \mathrm{~mm} \text {. A área } \\
\text { com o maior valor (> } 1.600 \mathrm{~mm} \text { ) de } \\
\text { precipitação está ao sul da bacia. Os } \\
\text { espaços com precipitações inferiores a } \\
1.200 \mathrm{~mm} \text { estão a leste, oeste, nordeste } \\
\text { (próximo a Guarapuava-PR) e sudeste } \\
\text { (próximo a Palmas-PR). }\end{array}$ \\
\hline
\end{tabular}




\begin{tabular}{|c|c|c|c|c|}
\hline 1986 & $\begin{array}{l}-0,5 \mathrm{a} \\
1,1^{\circ} \mathrm{C}\end{array}$ & & $\begin{array}{l}\text { Fase } \\
\text { Quente }\end{array}$ & $\begin{array}{c}\text { Os totais anuais oscilaram entre } 1.800 \text { e } \\
2.400 \mathrm{~mm} \text {, com os maiores valores ( }> \\
2.000 \mathrm{~mm} \text { ) de chuva localizados em uma } \\
\text { faixa no centro da bacia, de norte a sul, } \\
\text { com pontos isolados apresentando } 2.400 \\
\mathrm{~mm} \text {. Os espaços com valores inferiores a } \\
1.800 \mathrm{~mm} \text { se localizam a nordeste (bacia } \\
\text { do rio Cavernoso) e sudeste (próximo a } \\
\text { Palmas-PR). }\end{array}$ \\
\hline 1987 & $\begin{array}{l}1,1 \mathrm{a} \\
1,7^{\circ} \mathrm{C}\end{array}$ & $\begin{array}{c}\text { El Niño } \\
\text { Moderado }\end{array}$ & $\begin{array}{l}\text { Fase } \\
\text { Quente }\end{array}$ & $\begin{array}{c}\text { Assim como o ano anterior, as chuvas } \\
\text { oscilaram entre } 1.800 \text { e } 2.400 \mathrm{~mm} \text {, com } \\
\text { os maiores valores }(>2.200 \mathrm{~mm}) \\
\text { localizados em pontos isolados a norte e } \\
\text { a sudoeste da bacia. Os menores valores } \\
(<2.000 \mathrm{~mm}) \text { compreenderam espaços } \\
\text { na área central, leste e nordeste da } \\
\text { bacia. }\end{array}$ \\
\hline 1988 & $\begin{array}{l}-1,8 \mathrm{a} \\
0,8^{\circ} \mathrm{C}\end{array}$ & $\begin{array}{l}\text { La Niña } \\
\text { Moderado }\end{array}$ & $\begin{array}{l}\text { Fase } \\
\text { Quente }\end{array}$ & $\begin{array}{l}\text { Neste ano, as precipitações ficaram } \\
\text { abaixo da média, variando de } 1.200 \mathrm{a} \\
1.400 \mathrm{~mm} \text {. Os menores valores }(<1.200 \\
\mathrm{mm}) \text { se localizam na área central e a } \\
\text { oeste da bacia. }\end{array}$ \\
\hline 1989 & $\begin{array}{c}-1,7 \mathrm{a} \\
- \\
0,2^{\circ} \mathrm{C}\end{array}$ & & $\begin{array}{l}\text { Fase } \\
\text { Quente }\end{array}$ & $\begin{array}{c}\text { Os totais anuais oscilaram entre } 1.800 \text { e } \\
2.400 \mathrm{~mm} \text {. Os maiores valores (>2.200 } \\
\mathrm{mm} \text { ) de chuva se localizam ao sul do rio } \\
\text { Iguaçu, nas áreas mais elevadas, com } \\
\text { pontos isolados (a sudoeste e leste) } \\
\text { superando os } 2.400 \mathrm{~mm}\end{array}$ \\
\hline 1990 & $\begin{array}{l}0,1 \mathrm{a} \\
0,4^{\circ} \mathrm{C}\end{array}$ & & $\begin{array}{l}\text { Fase } \\
\text { Quente }\end{array}$ & $\begin{array}{l}\text { Um ano chuvoso, com totais anuais } \\
\text { variando de } 2.200 \text { a } 3.200 \mathrm{~mm} \text {. As áreas } \\
\text { que apresentam precipitação abaixo de } \\
2.200 \mathrm{~mm} \text { se localizam em pontos a } \\
\text { nordeste, noroeste e sudeste. Os } \\
\text { maiores valores de chuva se localizam ao } \\
\text { sul e sudoeste da bacia. }\end{array}$ \\
\hline 1991 & $\begin{array}{l}0,4 \mathrm{a} \\
1,5^{\circ} \mathrm{C}\end{array}$ & $\begin{array}{l}\text { El Niño } \\
\text { Fraco }\end{array}$ & $\begin{array}{l}\text { Fase } \\
\text { Quente }\end{array}$ & $\begin{array}{c}\text { As chuvas apresentaram variação de } \\
1.200 \text { a } 2.000 \mathrm{~mm} \text {. As precipitações } \\
\text { superaram os } 2.000 \mathrm{~mm} \text { em um ponto ao } \\
\text { norte da bacia, próximo à Cascavel-PR. } \\
\text { Já os menores índices }(<1.200 \mathrm{~mm}) \\
\text { estão ao sul e a oeste da bacia. }\end{array}$ \\
\hline 1992 & $\begin{array}{l}-0,3 \mathrm{a} \\
1,7^{\circ} \mathrm{C}\end{array}$ & $\begin{array}{c}\text { El Niño } \\
\text { Fraco }\end{array}$ & $\begin{array}{l}\text { Fase } \\
\text { Quente }\end{array}$ & $\begin{array}{l}\text { Em } 1992 \text { o regime de chuvas oscilou } \\
\text { entre } 1.800 \text { e } 2.600 \mathrm{~mm} \text {, com } \\
\text { precipitação abaixo de } 1.800 \text { no extremo } \\
\text { oeste e pontos com precipitações acima } \\
\text { de } 2.400 \mathrm{~mm} \text {, na área central, a } \\
\text { nordeste, sudeste e noroeste. }\end{array}$ \\
\hline
\end{tabular}




\begin{tabular}{|c|c|c|c|c|}
\hline 1993 & $\begin{array}{l}0,1 \mathrm{a} \\
0,7^{\circ} \mathrm{C}\end{array}$ & & $\begin{array}{l}\text { Fase } \\
\text { Quente }\end{array}$ & $\begin{array}{c}\text { As precipitações apresentaram variação } \\
\text { de } 1.800 \text { a } 2.600 \mathrm{~mm} \text {. Os totais anuais } \\
\text { exibiram chuvas acima de } 2.200 \mathrm{~mm} \text { na } \\
\text { área central e pontos a nordeste e } \\
\text { sudeste da bacia. As chuvas variaram } \\
\text { abaixo de } 2.000 \mathrm{~mm} \text { em áreas ao sul, } \\
\text { norte, oeste e extremo nordeste. }\end{array}$ \\
\hline 1994 & $\begin{array}{l}0,1 \mathrm{a} \\
1,1^{\circ} \mathrm{C}\end{array}$ & & $\begin{array}{l}\text { Fase } \\
\text { Quente }\end{array}$ & $\begin{array}{l}\text { As chuvas oscilaram entre } 1.800 \text { e } 2.600 \\
\text { mm. As áreas que exibem os máximos } \\
\text { anuais ( }>2.400 \mathrm{~mm} \text { ) estão a sul e } \\
\text { sudeste da bacia. Já os espaços com as } \\
\text { menores precipitações }(<2.000 \mathrm{~mm}) \\
\text { estão a oeste e nordeste. }\end{array}$ \\
\hline 1995 & $\begin{array}{l}-1 \mathrm{a} \\
1^{\circ} \mathrm{C}\end{array}$ & & $\begin{array}{l}\text { Fase } \\
\text { Quente }\end{array}$ & $\begin{array}{c}\text { Em } 1995 \text { as chuvas variaram entre } 1.400 \\
\text { e } 2.200 \mathrm{~mm} \text {, com uma área a nordeste } \\
\text { da bacia apresentando chuvas acima de } \\
2.000 \mathrm{~mm} \text {. Contanto, no restante da } \\
\text { bacia os totais anuais variaram abaixo de } \\
2.000 \mathrm{~mm} \text {, atingindo } 1.400 \mathrm{~mm} \text { no } \\
\text { extremo oeste, região de Foz do Iguaç- } \\
\text { PR. }\end{array}$ \\
\hline 1996 & $\begin{array}{c}-0,9 \mathrm{a} \\
- \\
0,4^{\circ} \mathrm{C}\end{array}$ & & $\begin{array}{l}\text { Fase } \\
\text { Quente }\end{array}$ & $\begin{array}{c}\text { No ano de } 1996 \text {, as chuvas variaram } \\
\text { entre } 2.000 \text { e } 3.000 \mathrm{~mm} \text {, com pontos } \\
\text { isolados a leste e a nordeste com totais } \\
\text { anuais abaixo de } 2.000 \mathrm{~mm} \text {. E o local } \\
\text { com chuva acima de } 3.000 \mathrm{~mm} \text { está em } \\
\text { um ponto na área central. }\end{array}$ \\
\hline 1997 & $\begin{array}{l}-0,4 \mathrm{a} \\
2,4^{\circ} \mathrm{C}\end{array}$ & $\begin{array}{l}\text { El Niño } \\
\text { Forte }\end{array}$ & $\begin{array}{l}\text { Fase } \\
\text { Quente }\end{array}$ & $\begin{array}{l}\text { Assim como no ano anterior, apresentou } \\
\text { chuvas acima da média, oscilando de } \\
2.000 \text { a } 2.800 \mathrm{~mm} \text {. Os menores valores } \\
\text { de precipitação (<2.000 mm) estão em } \\
\text { pontos isolados a oeste e a sudeste. No } \\
\text { sul da bacia está o maior valor de } \\
\text { precipitação (> } 2.800 \mathrm{~mm}) .\end{array}$ \\
\hline 1998 & $\begin{array}{l}-1,6 \mathrm{a} \\
2,2^{\circ} \mathrm{C}\end{array}$ & $\begin{array}{l}\text { La Niña } \\
\text { Fraco }\end{array}$ & $\begin{array}{l}\text { Fase } \\
\text { Quente }\end{array}$ & $\begin{array}{l}\text { O ano de } 1998 \text { é marcado por ser um dos } \\
\text { mais chuvosos da série e marca a } \\
\text { mudança de fase da ODP (fase quente } \\
\text { para fase fria). Os totais anuais oscilaram } \\
\text { de } 2.200 \text { a } 3.000 \text {. Onde os valores de } \\
\text { chuva abaixo de } 2.200 \text { mm estão no } \\
\text { extremo oeste da bacia e os maiores } \\
\text { valores (> } 3.000 \text { mm) estão a sul e } \\
\text { sudeste. }\end{array}$ \\
\hline 1999 & $\begin{array}{l}-1,5 \mathrm{a} \\
-1^{\circ} \mathrm{C}\end{array}$ & $\begin{array}{l}\text { La Niña } \\
\text { Moderado }\end{array}$ & Fase Fria & $\begin{array}{c}\text { O primeiro ano da fase fria da ODP } \\
\text { apresenta totais anuais abaixo da média. } \\
\text { A precipitação variou entre } 1.400 \text { e } 1.800 \\
\text { mm, com os menores valores }(<1.400 \\
\text { mm) no extremo oeste e sudeste. Os } \\
\text { maiores valores ( }>1.800 \mathrm{~mm} \text { ) se } \\
\text { localizam na área central, próximo à foz } \\
\text { do rio Chopim. } \\
\end{array}$ \\
\hline
\end{tabular}




\begin{tabular}{|c|c|c|c|c|}
\hline 2000 & $\begin{array}{c}-1,7 \mathrm{a} \\
- \\
0,6^{\circ} \mathrm{C}\end{array}$ & $\begin{array}{c}\text { La Niña } \\
\text { Fraco }\end{array}$ & Fase Fria & $\begin{array}{l}\text { Nesse ano as chuvas oscilaram próximas } \\
\text { a média, entre } 1.800 \text { e } 2.200 \mathrm{~mm} \text {. O } \\
\text { extremo oeste e um ponto ao sul da } \\
\text { bacia exibiram os menores valores }(< \\
1.800 \mathrm{~mm}) \text {. Já os maiores valores }(> \\
2.200 \mathrm{~mm} \text { ) estão a sudeste e leste. }\end{array}$ \\
\hline 2001 & $\begin{array}{c}-0,7 \mathrm{a} \\
- \\
0,3^{\circ} \mathrm{C}\end{array}$ & & Fase Fria & $\begin{array}{c}\text { O regime de chuvas apresentou variação } \\
\text { entre } 1.600 \text { e } 2.200 \mathrm{~mm} \text {, com os maiores } \\
\text { valores (> } 2.200 \mathrm{~mm} \text { ) localizados a } \\
\text { nordeste, sudoeste, sudeste e na área } \\
\text { central da bacia. O espaço com } \\
\text { precipitação abaixo de } 1.600 \mathrm{~mm} \text { está no } \\
\text { extremo oeste da bacia, próximo à foz do } \\
\text { rio lguaçu. }\end{array}$ \\
\hline 2002 & $\begin{array}{l}0,1 \mathrm{a} \\
1,3^{\circ} \mathrm{C}\end{array}$ & $\begin{array}{c}\text { El Niño } \\
\text { Fraco }\end{array}$ & Fase Fria & $\begin{array}{c}\text { Os totais anuais oscilaram entre } 2.000 \text { e } \\
2.400 \mathrm{~mm} \text {, com os menores valores }(< \\
2.000 \mathrm{~mm} \text { ) a norte, nordeste e sudeste } \\
\text { da bacia. Já os maiores valores estão na } \\
\text { área central, a leste e sudoeste. }\end{array}$ \\
\hline 2003 & $\begin{array}{l}-0,3 \mathrm{a} \\
0,9^{\circ} \mathrm{C}\end{array}$ & & Fase Fria & $\begin{array}{c}\text { As precipitações exibiram oscilação entre } \\
1.600 \text { e } 2.000 \mathrm{~mm} \text {. Com os maiores } \\
\text { índices }(>2.000 \mathrm{~mm}) \text { localizados a } \\
\text { sudoeste, noroeste e nordeste. Já os } \\
\text { menores valores }(<1.600 \mathrm{~mm}) \mathrm{se} \\
\text { localizam a sudeste. }\end{array}$ \\
\hline 2004 & $\begin{array}{l}0,3 \mathrm{a} \\
0,7^{\circ} \mathrm{C}\end{array}$ & & Fase Fria & $\begin{array}{c}\text { No ano de } 2004 \text { as precipitações } \\
\text { oscilaram entre } 1.400 \text { (oeste) e } 2.000 \mathrm{~mm} \\
\text { (leste). Contanto, na maior parte da área } \\
\text { central da bacia, as chuvas variaram } \\
\text { entre } 1.600 \text { e } 1.800 \mathrm{~mm} \text {. }\end{array}$ \\
\hline 2005 & $\begin{array}{l}-0,8 \mathrm{a} \\
0,6^{\circ} \mathrm{C}\end{array}$ & & Fase Fria & $\begin{array}{l}\text { Em } 2005 \text { o regime de chuvas oscilou } \\
\text { próximo à média, entre } 1.800 \text { e } 2.200 \\
\text { mm. Os espaços que exibiram } \\
\text { precipitação acima de } 2.200 \text { (leste, oeste, } \\
\text { sudeste e sudoeste) ou abaixo de } 1.800 \\
\text { mm (norte e extremo oeste) estão em } \\
\text { pontos isolados. }\end{array}$ \\
\hline 2006 & $\begin{array}{l}-0,8 \mathrm{a} \\
0,9^{\circ} \mathrm{C}\end{array}$ & & Fase Fria & $\begin{array}{c}\text { Um ano com chuvas abaixo da média, } \\
\text { oscilando entre } 1.400 \text { e } 1.800 \mathrm{~mm} \text {. As } \\
\text { áreas com chuvas abaixo de } 1.400 \mathrm{~mm} \\
\text { se localizam a sudeste e alguns pontos } \\
\text { isolados ao norte, nordeste e oeste. Os } \\
\text { espaços com precipitações acima de } \\
1.800 \mathrm{~mm} \text { estão em pontos isolados a } \\
\text { norte e sudoeste da bacia. }\end{array}$ \\
\hline
\end{tabular}




\begin{tabular}{|c|c|c|c|c|}
\hline 2007 & $\begin{array}{l}-1,6 \mathrm{a} \\
0,7^{\circ} \mathrm{C}\end{array}$ & $\begin{array}{c}\text { La Niña } \\
\text { Fraco }\end{array}$ & Fase Fria & $\begin{array}{c}\text { No ano de } 2007 \text { o regime de chuvas } \\
\text { apresentou características distintas, no } \\
\text { sul da bacia as chuvas oscilaram acima } \\
\text { de } 2.000 \mathrm{~mm} \text {, chegando a } 2.400 \mathrm{~mm} \text { a } \\
\text { sudeste e sudoeste enquanto ao norte da } \\
\text { bacia o regime de chuvas oscilou abaixo } \\
\text { de } 1.800 \mathrm{~mm} \text {, chegando a } 1.600 \mathrm{~mm} \text { em } \\
\text { pontos ao norte, nordeste e extremo } \\
\text { oeste. }\end{array}$ \\
\hline 2008 & $\begin{array}{c}-1,6 \mathrm{a} \\
- \\
0,5^{\circ} \mathrm{C}\end{array}$ & $\begin{array}{l}\text { La Niña } \\
\text { Fraco }\end{array}$ & Fase Fria & $\begin{array}{l}\text { Em } 2008 \text { as chuvas oscilaram entre } \\
1.200 \text { (oeste) e } 2.000 \mathrm{~mm} \text { (sudoeste). } \\
\text { Contudo, esses valores estão em pontos } \\
\text { isolados. Na área central, as chuvas } \\
\text { oscilaram entre } 1.600 \text { e } 1.800 \mathrm{~mm} \text {. }\end{array}$ \\
\hline 2009 & $\begin{array}{l}-0,8 \mathrm{a} \\
1,6^{\circ} \mathrm{C}\end{array}$ & $\begin{array}{l}\text { El Niño } \\
\text { Fraco }\end{array}$ & Fase Fria & $\begin{array}{l}\text { Os totais anuais oscilaram de } 2.000 \mathrm{a} \\
2.400 \mathrm{~mm} \text {. Onde os menores valores (< } \\
2.000 \mathrm{~mm} \text { ) estão a leste e oeste da } \\
\text { bacia. Os maiores valores se concentram } \\
\text { em pontos na área central, a nordeste e } \\
\text { sudoeste. }\end{array}$ \\
\hline 2010 & $\begin{array}{l}-1,7 \mathrm{a} \\
1,5^{\circ} \mathrm{C}\end{array}$ & $\begin{array}{l}\text { La Niña } \\
\text { Moderado }\end{array}$ & Fase Fria & $\begin{array}{c}\text { No ano de } 2010 \text { as chuvas apresentaram } \\
\text { características semelhantes ao ano de } \\
2008 \text {, quando os maiores valores de } \\
\text { precipitação (> 2.000 mm) estão ao sul } \\
\text { do rio lguaçu, chegando a superar } 2.200 \\
\text { mm a sudoeste e sudeste. Ao norte do rio } \\
\text { Iguaçu as chuvas oscilaram abaixo de } \\
1.800 \mathrm{~mm}\end{array}$ \\
\hline 2011 & $\begin{array}{c}-1,4 \mathrm{a} \\
- \\
0,6^{\circ} \mathrm{C}\end{array}$ & $\begin{array}{l}\text { La Niña } \\
\text { Fraco }\end{array}$ & Fase Fria & $\begin{array}{c}\text { As precipitações apresentaram variação } \\
\text { de } 1.600 \text { a } 2.400 \mathrm{~mm} \text {. Os pontos de } \\
\text { precipitação que superaram os } 2.400 \\
\text { mm, foram na área central, a sudeste e } \\
\text { sudoeste. Já o menor valor (1.600 mm) } \\
\text { está no extremo Oeste, próximo à divisa } \\
\text { com o Paraguai. }\end{array}$ \\
\hline 2012 & $\begin{array}{l}-0,8 \mathrm{a} \\
0,3^{\circ} \mathrm{C}\end{array}$ & & Fase Fria & $\begin{array}{l}\text { Os totais anuais de } 2012 \text { ficaram entre } \\
1.400 \text { (extremo Oeste) e } 2.000 \mathrm{~mm} \\
\text { (Sudoeste). Porém, os valores mínimos e } \\
\text { máximos estão em pontos isolados, pois } \\
\text { predominam na bacia chuvas entre } 1.600 \\
\text { e } 1.800 \mathrm{~mm} \text {. }\end{array}$ \\
\hline 2013 & $\begin{array}{c}-0,4 \mathrm{a} \\
- \\
0,3^{\circ} \mathrm{C}\end{array}$ & & Fase Fria & $\begin{array}{l}\text { O regime de chuvas oscilou de } 2.000 \text { a } \\
2.400 \mathrm{~mm} \text {. O menor valor }(<2.000 \mathrm{~mm}) \\
\text { de precipitação está no extremo oeste, } \\
\text { próximo à Foz do lguaçu-PR. Já os } \\
\text { maiores valores }(>2.400 \mathrm{~mm}) \text { estão na } \\
\text { área central e a sudoeste. }\end{array}$ \\
\hline 2014 & $\begin{array}{l}-0,4 a \\
0,7^{\circ} \mathrm{C}\end{array}$ & & Fase Fria & $\begin{array}{l}\text { Um ano chuvoso, com os totais anuais } \\
\text { variando de } 2.200 \text { (nordeste) a } 2.800 \mathrm{~mm} \\
\text { (norte). Porém, apesar dos extremos, } \\
\text { predominam na bacia os totais entre } \\
2.400 \text { e } 2.600 \mathrm{~mm} \text {. }\end{array}$ \\
\hline
\end{tabular}




\begin{tabular}{|c|c|c|c|c|}
\hline 2015 & $\begin{array}{l}0,6 \mathrm{a} \\
2,6^{\circ} \mathrm{C}\end{array}$ & $\begin{array}{c}\text { El Niño } \\
\text { Moderado }\end{array}$ & Fase Fria & $\begin{array}{c}\text { As precipitações variaram de } 1.800 \\
\text { (extremo oeste) a } 2.600 \mathrm{~mm} \text { (área central } \\
\text { e sudoeste). Os valores de chuva que } \\
\text { predominam na bacia estão entre } 2.200 \text { e } \\
2.400 \mathrm{~mm} \text {. }\end{array}$ \\
\hline 2016 & $\begin{array}{l}-0,7 \mathrm{a} \\
2,5^{\circ} \mathrm{C}\end{array}$ & & Fase Fria & $\begin{array}{c}\text { Em } 2016 \text { os totais anuais oscilaram entre } \\
1.600 \text { e } 2.200 \mathrm{~mm} \text {. Os pontos da bacia } \\
\text { que superam os } 2.000 \mathrm{~mm} \text { estão na área } \\
\text { central, ao norte e sul. Já o ponto com } \\
\text { menor valor de precipitação }(<1.600 \\
\mathrm{mm} \text { ) está a oeste. }\end{array}$ \\
\hline
\end{tabular}

Fonte: ANA, 2019, INPE, 2019, NOOA, 2019 e MOLION, 2005.

\section{Discussão}

Como observado, os totais anuais de precipitação da BHBRI apresentam grande variabilidade. Constata-se que a ODP interfere no regime chuvas, tendo em vista que ela concentra períodos de ocorrência de El Niños (fase quente) e La Niñas (fase fria). Contudo, há uma divergência quanto ao início da fase quente. Molion (2005), citando Mantua et al. (1997), afirma que os eventos de ODP persistem por 20 ou 30 anos, sendo o ano de 1976 o fim de uma fase fria, a qual teria se iniciado em 1947. Porém, na BHBRI os anos de 1976, 1977 e 1978 apresentam precipitações abaixo da média, mesmo que a TSM oscilasse positivamente no período. Desta forma, podemos afirmar que na área de estudo, a fase quente da ODP iniciou no ano de 1979 e os anos anteriores (1976 a 1978) ainda estavam sobre influência das fortes variações negativas da fase fria da ODP.

Essa alteração no ano de início da fase quente da ODP já foi abordada por Nascimento Junior ${ }^{9}$ (2011) e Buffon e Binda ${ }^{10}$ (2013), onde, em seus trabalhos abordavam municípios próximos ou dentro da BHBRI. Logo, esta configuração pode significar que "os fenômenos de teleconexões (ODP e ENOS, principalmente) apresentam um caráter dinâmico em relação à temporalidade, e por isso sua repercussão e influência não são observados instantaneamente na variabilidade" (NASCIMENTO JUNIOR, 2011, p.79). Cabe salientar ainda o trabalho de Binda (2016), na bacia hidrográfica do Arroio Miracatu (RS), onde o autor comprovou um atraso de cinco anos no início e fim de cada fase da ODP.

\footnotetext{
${ }^{9}$ Dados dos municípios de São Miguel do Iguaçu-PR, Foz do Iguaçu-PR e Quedas do Iguaçu-PR, com início da ODP em 1973, 1979 e 1980 respectivamente.

10 Dados do município de Abelardo Luz-SC, indicam início da ODP em 1979.
} 
Desta forma, na BHBRI, a fase quente da ODP perdurou entre 1979 e 1998, fase essa marcada pelo excesso de chuvas em diversos anos da série $(1982,1983$, 1990, 1992, 1996, 1997 e 1998). Cabe destaque ao ano de 1983 por se tratar de um ano extremamente chuvoso, onde todas as estações pluviométricas exibiram precipitações acima da média normal. Esses anos com aumento das chuvas estão ligados aos eventos de El Niño Moderado e Forte, ou seja, quando a TSM oscila acima de $1^{\circ} \mathrm{C}$. O ano de 1983 foi considerado excepcional e as precipitações superaram os valores normais de modo significativo (BERLATO; FONTANA, 2001, ANDRADE, 2003, AZEVEDO, 2006, NASCIMENTO JUNIOR, 2011, BUFFON; BINDA, 2013).

O ano de 1998 apresenta classificação de La Niña Fraco, pois predominou durante $\mathrm{o}$ ano, meses com a TSM entre $-0,5$ e $-1^{\circ} \mathrm{C}$, contudo, as chuvas dos primeiros cinco meses do ano, ainda sobre influência do El Niño Forte que se iniciou em 1997, foram representativas, exibindo variações acima da média anual de chuvas.

Ainda na fase quente, cabe destaque aos anos com precipitação abaixo da média (1985 e 1988). O ano de 1988 estava sobre influência de um evento de La Niña moderado, com redução da TSM em até $-1,8^{\circ} \mathrm{C}$. Já o ano de 1985 , também exibiu redução da TSM, até $-1,1^{\circ} \mathrm{C}$, classificando o episódio como La Niña fraco.

Nesse período (1979 a 1998), o aumento nos totais de chuva e concentração de anos com precipitação acima da média já foi enfatizado no Oeste Catarinense (BUFFON; BINDA, 2013) e Oeste e Sudoeste Paranaense (ANDRADE, 2003, SOUZA, 2006 e NASCIMENTO JUNIOR, 2011).

A fase fria da ODP se iniciou no ano de 1999 e se estende até 2016 (último ano abordado no trabalho). Nesse período, há uma diminuição da quantidade e intensidade dos anos chuvosos, havendo maior ocorrência de eventos de La Niña. Porém, nem todos os anos que a TSM oscila negativamente ocorre redução nos totais anuais de chuva, como em 2007 e 2009, quando várias estações pluviométricas, principalmente as localizadas ao sul do rio Iguaçu revelam chuvas acima da média.

Os eventos de La Niña que apresentaram redução nas chuvas foram 1999 e 2008. Além desses anos, 2006 e 2012 também apresentaram diminuição nas chuvas, porém, mesmo a TSM oscilando negativamente em alguns meses, em ambos, não se caracteriza nenhum evento. 
Na fase fria da ODP verificam-se poucos eventos de El Niño. Nos eventos de 2002, 2009 e 2015, os totais anuais de chuva expressaram aumento. Em 2015, destaca-se além do excesso de chuvas, os anos que antecedem (2013 e 2014) por apresentarem características chuvosas, mesmo a TSM variando próximo a média normal.

Assim como na fase quente da ODP, a fase fria acompanha as variações (totais anuais de chuva) apresentadas por outros autores (ANDRADE, 2003, SOUZA, 2006 E NASCIMENTO JUNIOR, 2011 e BUFFON; BINDA, 2013), nos anos com características secas (1999, 2004, 2006, 2008 e 2012), com precipitações abaixo da média.

As anomalias de precipitação, tanto negativas quanto positivas, em anos que a TSM indica presença do ENOS, são explicadas pelos sistemas de circulação causadores de chuva, pois operam anualmente com uma frequência similar sobre a Região Sul do Brasil e no Oeste do Paraná. O decréscimo na frequência de correntes perturbadas do Sul (Frente Polar), são compensadas pelas correntes perturbadas de Oeste (linhas de instabilidade tropicais) no verão (NIMER, 1979).

A respeito dos parâmetros estatísticos, a média de precipitação fica entre 1.800 e $2.000 \mathrm{~mm}$ anuais. Essa média ficou superior àquela proposta por Nimer (1979), em que as médias anuais oscilavam entre 1.500 (norte do rio Iguaçu) e $1.750 \mathrm{~mm}$ (sul do rio Iguaçu), haja vista que o período abordado no trabalho foi de 1914 até 1938. Já em trabalhos mais recentes (AZEVEDO, 2006, NOGAROLLI, 2007, SOUZA, 2006) os valores se assemelham, com variações de acordo com o período abordado.

Nos trabalhos de Nery, Baldo e Klosowski (1997), Azevedo (2006) e Souza (2006) foi utilizado o método Ward para determinar áreas homogêneas de precipitação, ou seja, mapear as estações pluviométricas que apresentam características semelhantes entre si. Nery, Baldo e Klosowski (1997) dividiram o estado do Paraná em cinco grupos homogêneos e Souza (2006) em quatro. Em ambos a BHBRI se concentra em um único grupo. Azevedo (2006), por sua vez, aplicou o método apenas na bacia hidrográfica do rio Iguaçu, resultando em três grupos homogêneos de precipitação, dois deles dividindo a área do baixo rio Iguaçu.

Esses grupos propostos por Azevedo (2006) coincidem com as áreas que expõem os maiores (acima de $2.000 \mathrm{~mm}$ ) e menores (abaixo de $2.000 \mathrm{~mm}$ ) valores de média de precipitação. O principal responsável pelo aumento dos totais anuais de precipitação na BHBRI, seria, portanto, o relevo, por "sua influência se destaca 
principalmente no Planalto das Araucárias, próximo dos municípios de Guarapuava e Palmas, onde à altitude chega a $1.200 \mathrm{~m}$, propiciando a formação das chuvas orográficas, a partir da dinâmica de entrada de massas polares" (AZEVEDO, 2006, p.63).

O desvio padrão também acompanha os limites propostos por Azevedo (2006) para os grupos homogêneos, onde os valores de 400 a $450 \mathrm{~mm}$ estão ao sul, sudeste, nordeste e área central e os menores valores de desvios padrão (abaixo de $400 \mathrm{~mm}$ ) se localizam ao norte e oeste da BHBRI.

\section{Considerações Finais}

Considerando o acima exposto, é possível afirmar que os eventos de El Niño de intensidade moderada e forte apresentam chuvas acima da média em praticamente toda área da BHBRI. Já os eventos de La Niña, moderados e fracos, não causam necessariamente a redução das precipitações, por vezes variando acima ou próximo da média, sem caracterizar uma tendência.

É possível observar que a BHBRI não apresentou período seco ou chuvoso ao longo do período estudado. O regime de chuvas apresenta grande variabilidade interanual associadas a eventos vinculados a fenômenos de escala global. Esses eventos representam aumento ou diminuição da precipitação de acordo com a região do globo.

Constatou-se que a ODP exerceu uma influência no regime de chuvas, mudando os eventos associados ao ENOS. Na BHBRI, o início da fase quente foi no ano de 1979 e perdurou até 1998, concentrando diversos episódios de El Niños moderados e fortes.

Já a fase fria da ODP foi de 1999 até 2016, reduzindo os episódios de El Niño e aumentando os de La Niña. Nos quatro anos com precipitações abaixo da média, dois (1999 e 2008) estão relacionados aos eventos de La Niña e os outros dois (2006 e 2012) são considerados habituais.

A respeito dos parâmetros estatísticos, a precipitação média da bacia fica entre 1.800 e $2.000 \mathrm{~mm}$, com as maiores médias na área central, a sul, nordeste e uma faixa ao norte da BHBRI. Já os valores mais elevados de desvio padrão e coeficiente de variação estão na Região Sul e um ponto a nordeste da bacia hidrográfica. 
Ademais, os trabalhos futuros terão por objetivo análises sazonais, focando na dinâmica e sistemas atmosféricos.

\section{REFERÊNCIAS}

AGUASPARANÁ. Instituto de águas do Paraná. Disponível em: <www.aguasparana.pr.gov.br/>. Acesso em: 13 Fev. 2020.

ALVES, Elis D.L.; VECCHIA, Francisco A.S. Análise de diferentes métodos de interpolação para a precipitação pluvial no Estado de Goiás. Acta Scientiarum. Human And Social Sciences, [s.I.], v. 33, n. 2, p.193-197, 19 dez. 2011.

ANA. Agência Nacional de Águas. Disponível em: <www3.ana.gov.br/> Acesso em: 28 Jun. 2019.

ANDRADE, A.R de. Variabilidade da precipitação pluviométrica na Bacia hidrográfica do Ivaí - Paraná. Dissertação de mestrado. Maringá: UEM, 2003. 99p.

ANTUNES, Adriano de Souza. Fenômenos de precipitação pluvial intensa: análise da espacialidade e variabilidade na bacia hidrográfica do rio Piracicaba-SP. 2015. $103 \mathrm{f}$. Dissertação (Mestrado) - Curso de Geografia Física, Universidade de São Paulo, São Paulo, 2015.

AZEVEDO, Luiz C. de. Análise da precipitação pluvial da bacia do rio IguaçuParaná. 2006. 109 f. Dissertação (Mestrado) - Curso de Geografia, Universidade Estadual de Maringá, Maringá, 2006.

BERLATO, Moacir A.; FONTANA, Denise C. EL NIÑO e LA NIÑA: Impactos no clima, na vegetação e na agricultura do Rio Grande do sul. Aplicações de previsões climáticas na agricultura. Porto Alegre: UFRGS, 2001. 110 p.

BERTONI, Juan C.; TUCCI, Carlos E. M. PRECIPITAÇÃO. In: TUCCI, Carlos E. M. (Org.). HIDROLOGIA: ciência e aplicação. 4. ed. Porto Alegre: UFRGS/ABRH, 2009. p. 177-243.

BINDA, Andrey Luis. Eventos hidrológicos extremos e morfodinâmica fluvial em área afetada por processos de arenização no sudoeste do Rio Grande do Sul - bacia hidrográfica do Arroio Miracatu. 2016. 292 f. Tese (Doutorado) - Curso de Geografia, UFRGS, Porto Alegre, 2016.

BUFFON, E.A.M.; BINDA, A.L. Variabilidade no regime pluvial em Abelardo Luz (SC) no período de 1958 a 2008: interações entre mecanismos de teleconexão decadal e interanual. Revista Brasileira de Climatologia, v. 13, p. 285-297, 2013.

CARVALHO, José R.P. de.; ASSAD, Eduardo D. Análise espacial da precipitação pluviométrica no Estado de São Paulo: comparação de métodos de interpolação. Engenharia Agrícola, [s.I.], v. 25, n. 2, p.377-384, ago. 2005.

CONTI, José B. Considerações sobre mudanças climáticas globais. In: SANT'ANNA NETO, J.L., ZAVATINI, J.A. Variabilidade e mudanças climáticas: implicações ambientais e socioeconômicas. Maringá: EDUEM, 2000. p. 17-28.

CPTEC - Centro de Previsão do Tempo e Estudos Climáticos. Disponível em: < https://www.cptec.inpe.br/ >. Acesso em: 13 de Fev. 2020. 
GARCEZ, Lucas N.; ALVAREZ, Guillermo Acosta. Hidrologia. 2. ed. São Paulo: Edgard Blucher, 1988. 291 p.

GRIMM, A. M. Clima da região Sul do Brasil. In: CAVALCANTI, I.F.A. et al. (Org) Tempo e Clima no Brasil. São Paulo: Oficina de Textos, 2009. Cap. 17, p. 259-275.

HOLTZ, A. C. Tatit. Precipitação. In: PINTO, Nelson L. de Sousa et al. Hidrologia Básica. 15. ed. São Paulo: Edgard Blucher, 2014. Cap. 2. p. 7-35. Reimpressão.

IBGE - Instituto Brasileiro de Geografia e Estatística. Disponível em: <https://www.ibge.gov.br/>. Acesso em: 28 Jun. 2020.

ITCG - Instituto de Terras, Cartografia e Geologia do Paraná. Disponível em: <http://www.mineropar.pr.gov.br/>. Acesso em: 28 Jun. 2019.

KAYANO, Mary T.; ANDREOLI, Rita V. Variabilidade Decenal a Multidecenal. In: CAVALCANTI, Iracema Fonseca de Albuquerque et al (Org.). Tempo e Clima: no Brasil. São Paulo: Oficina dos Textos, 2009. P. 127-134.

MAACK, Reinhard. Geografia física do estado do Paraná. 2. ed. Rio de Janeiro: Livraria José Olympio Editora, 1981. 450 p.

MAZZINI, P.L.F.; SCHETTINI, C. A. F. Avaliação de metodologias de interpolação espacial aplicadas a dados hidrográficos costeiros quase sinóticos. Brazilian Journal of Aquatic Science and Technology, v. 13, n. 1, p. 53-64, 2009.

MENDONÇA, F.A.; DANNI-OLIVEIRA, I.M. Climatologia: noções básicas e climas do Brasil. São Paulo: Oficina de Textos, 2007.

MOLION, Luiz C.B. Aquecimento global, el Niños, manchas solares, vulcões e oscilação decadal do pacífico. Revista Climanálise, [s. L.], p.1-5, ago. 2005.

NASCIMENTO JÚNIOR, L. As chuvas no Paraná: variabilidade interanual e decadal. 2011. 87 p. Trabalho de conclusão de curso em Geografia - Universidade Estadual de Londrina, Londrina, 2011.

NERY, Jonas T.; BALDO, Maria C.; KLOSOWSKI, Élcio S. Aplicação do coeficiente de variação na precipitação pluviométrica no estado do Paraná. Revista Unimar, [s/l], v. 19, n. 4, p.1125-1131, 1997.

NIMER, Edmon. Climatologia do Brasil. Rio de Janeiro: IBGE, 1979. 422 p.

NOGAROLLI, Mozart. Evolução climática do estado do Paraná: 1970 - 1999. 2007. 129 f. Dissertação (Mestrado) - Curso de Geografia, Ciências da Terra, Universidade Federal do Paraná, Curitiba, 2007.

NOAA - National Oceanic and Atmospheric Administration. Disponível em: < https://www.noaa.gov/ >. Acesso em: 13 de Fev. 2020.

OLIVEIRA, Gilvan S. O EI Niño e Você: O Fenômeno Climático. São José dos Campos: Transtec Editorial, 1999. $116 \mathrm{p}$.

SILVA, M. V. da.; CAMPOS, C. R. J. de. Anomalias decadais do regime hídrico do RS no período de 1977 a 2006. Ciência e Natura, UFSM, 33 (1), 2011. p.75-89. 
SOUSA, Patrícia de. Estudo da variabilidade da precipitação no estado do Paraná associado à anomalia da TSM no oceano Pacífico. 2006. 72 f. Dissertação (Mestrado) Curso de Geografia, Universidade Estadual de Maringá, Maringá, 2006.

VIOLA, Marcelo R. et al. Métodos de interpolação espacial para o mapeamento da precipitação pluvial. Revista Brasileira de Engenharia Agrícola e Ambiental, [s.I.], v. 14, n. 9, p.970-978, set. 2010.

ZAVATTINI, João A.; BOIN, Marcos Norberto. Climatologia Geográfica: Teoria e Prática de Pesquisa. Campinas: Alínea, 2013. 151 p.

\section{NOTAS DE AUTOR}

\section{CONTRIBUIÇÃO DE AUTORIA}

Anderson Borges - Coleta de dados, análise de dados, concepção e elaboração do manuscrito, participação ativa da discussão dos resultados; revisão e aprovação da versão final do trabalho.

Andrey Luis Binda - Análise de dados, concepção e elaboração do manuscrito, participação ativa da discussão dos resultados; revisão e aprovação da versão final do trabalho.

Rafaela Harumi Fujita - Análise de dados, concepção e elaboração do manuscrito, participação ativa da discussão dos resultados; revisão e aprovação da versão final do trabalho.

\section{FINANCIAMENTO}

O presente trabalho foi realizado com apoio da Coordenação de Aperfeiçoamento de Pessoal de Nível Superior Brasil (CAPES) - Código de Financiamento 001.

\section{CONSENTIMENTO DE USO DE IMAGEM}

Não se aplica.

\section{APROVAÇÃO DE COMITÊ DE ÉTICA EM PESQUISA \\ Não se aplica.}

\section{CONFLITO DE INTERESSES}

Não se aplica.

\section{LICENÇA DE USO}

Este artigo está licenciado sob a Licença Creative Commons CC-BY. Com essa licença você pode compartilhar, adaptar, criar para qualquer fim, desde que atribua a autoria da obra.

\section{HISTÓRICO}

Recebido em: 14-02-2020

Aprovado em: 08-12-2020 